\title{
Veri Merkezi Güvenliğinin Sağlanmasında IoT Sensörlerinin Kullanımı Üzerine Bir Uygulama
}

\author{
Fatih Çağatay $\mathrm{Baz}^{1 *}$, Kadir Uludağ ${ }^{2}$ \\ 1* Osmaniye Korkut Ata Üniversitesi, İktisadi ve İdari Bilimler Fakültesi, Yönetim Bilişim Sistemleri Bölümü, Osmaniye, Türkiye, (ORCID: 0000-0002-6398-9851), \\ fatihcagataybaz@osmaniye.edu.tr \\ ${ }^{2}$ Osmaniye Korkut Ata Üniversitesi, İktisadi ve İdari Bilimler Fakültesi, Yönetim Bilişim Sistemleri Bölümü, Osmaniye, Türkiye, (ORCID: 0000-0002-7359-1396), \\ kuludag@osmaniye.edu.tr
}

(İlk Geliş Tarihi 19 Mayıs 2021 ve Kabul Tarihi 10 Eylül 2021)

(DOI: $10.31590 /$ ejosat.939216)

ATIF/REFERENCE: Baz, F. Ç. \& Uludağ, K. (2021). Veri Merkezi Güvenliğinin Sağlanmasında IoT Sensörlerinin Kullanımı Üzerine Bir Uygulama. Avrupa Bilim ve Teknoloji Dergisi, (27), 392-397.

$\ddot{O} \mathbf{z}$

Gün geçtikçe dijitalleşen yaşamımızda akıllı sistemler artık hayatımızın vazgeçilmez bir parçası haline gelmiştir. Evlerde kullanılmakta olan eşyalar; ulaşım araçları, akıllı sensör ve sistemler ile donatılmaya başlanmıştır. Akıllı sistemler ile yapay zekâ teknolojilerindeki gelişmeler üretim sektöründe de Endüstri 4.0 devrimini gerçekleştirmiştir. Tüm bu gelişmeler Nesnelerin İnterneti yani IoT olarak ifade edilen dijital inovasyonun gerçekleşmesidir. Bu sayede güvenlik senaryoları kendi aralarında iletişim kurabilen cihazlar ile hızlı ve güvenli bir şekilde sağlanmaktadır. Bu çalışmada Nesnelerin İnterneti (Internet of Things-IOT) uygulamaları için geliştirilen Raspberry Pi ve Arduino kartları ile birtakım sensörler kullanarak açık kaynak kodlu veri merkezi izleme uygulaması hayata geçirilmiştir. Çalışmada 64 bit işlemciye sahip Raspberry Pi 3 B+ ve Arduino Nano geliştirme kartlarının yanı sıra, hareket algılama, 1s1-nem sensörleri, RC522 RFID modül, kamera, röle, led, buzzer ve I2C LCD ekran kullanılmıştır. Geliştirilen sistemde veri merkezlerinin izlenmesi için gerekli olan temel fonksiyonların başarılı bir şekilde gerçekleştirildiği gözlenmiştir.

\section{An Application on the Use of IoT Sensors to Ensure Date Center Security}

\begin{abstract}
Smart systems have become an indispensable part of our lives in our day by day digitalizing life. Items used in homes; transportation vehicles started to be equipped with smart sensors and systems. Developments in smart systems and artificial intelligence technologies have also made the Industry 4.0 revolution in the production sector. All these developments are the realization of digital innovation expressed as the Internet of Things, ie IoT. In this way, security scenarios are provided quickly and securely with devices that can communicate with each other. In this study, an open source data center monitoring application was implemented using some sensors with Raspberry Pi and Arduino boards developed for Internet of Things (IOT) applications. In the study, besides Raspberry Pi $3 \mathrm{~B}+$ and Arduino Nano development boards with 64 bit processors, motion detection, temperature-humidity sensors, RC522 RFID module, camera, relay, led, buzzer and I2C LCD screen were used. It has been observed that the basic functions required for monitoring data centers were successfully performed in the developed system.
\end{abstract}

Keywords: Data center security, Raspberry pi, Arduino, Sensor, Cacti, IoT.

\footnotetext{
*Sorumlu Yazar: fatihcagataybaz@osmaniye.edu.tr
} 


\section{Giriş}

Nesnelerin interneti kavramı basit tanımıyla fiziksel aygıtların birbiri arasında ya da daha büyük sistemlerle bağlantı kurarak veri alışverişinde bulunduğu iletişim ağıdır. Veri depolama ve iletişim teknolojilerindeki gelişmelere paralel olarak günümüzde endüstriyel üretim, bilişim, eğitim, sağlık, tarım, akıllı ev uygulamaları gibi birçok alanda kullanılmakta olan bu teknolojinin temel görevi gerçek dünya ile sanal dünya arasında bir köprü vazifesi görmesidir (Baz, 2018, Carrillo ve ark., 2015, Wikipedia, 2021).

Nesnelerin İnterneti teknolojisi fiziksel, işlem, ağ ve uygulama olmak üzere dört katmanlı bir mimari yapıdan oluşur. Bazı araştırmacılar bu dört katmana ek olarak iş katmanı adı verilen bir katman daha eklemişlerdir. Gerçek dünyadan verileri toplamamızı sağlayan sensörler en alt katman olan fiziksel katmanı oluşturur (Hammami, 2019). Nesnelerin İnterneti teknolojisindeki çarpıcı gelişmelerden biri de ağ katmanında meydana gelen yeniliklerdir. Son yıllarda özellikle mobil ağların yaygınlaşması ile internete bağlı cihazların sayısında çok önemli bir artış meydana gelmiştir. Ericsson tarafından yapılan bir araştırmaya göre 2025 yılına kadar 5 milyar IoT cihazın hücresel ağ üzerinden internete bağlanacağı öngörülmektedir (Liu ve ark., 2016, www.ericsson.com, 2021).

Nesnelerin İnterneti teknolojisinde nesneler birbirleriyle RFID, ZigBee, WPAN, WSN, DSL, UMTS, GPRS, WiFi, WiMax, LAN, WAN, 3G gibi kablolu ya da kablosuz bağlantı protokollerini kullanarak iletişim kurarlar. Bu şekilde nesneler birbiriyle etkileşim haline girer ancak etkileşim tek başına yeterli değildir. Kendi kendine bilgiyi işleme, yapılandırma ve karar verebilme nesneleri akıllı hale getirir. Böylelikle insandan-insana doğru başlayan etkileşim süreci, insandan-nesneye, sonrasında da nesneden-nesneye evrilir (Tan ve ark., 2010).

\subsection{Nesnelerin İnterneti Kavramı (Internet of Things - IoT)}

İlk IoT cihazı olarak kabul edilen ve internet üzerinden açılıp kapatılabilen ekmek kızartma makinası 1990 yılında John Romkey tarafından geliştirilmiştir (Romkey, 2017). 1991 yılında Tim Berners-Lee ilk web sayfasını yayınlamıştır. Asıl dönüm noktası ise 1999 yılı olmuştur. Zira Kevin Ashton, UPC barkod sistemini değiştirmeye yönelik olarak RFID tabanlı stok yönetim sistemi çalışmalarında ilk defa "Nesnelerin İnterneti" terimini kullanmıştır. 2005 yılında Uluslararası Telekomünikasyon Birliğinin konu hakkındaki ilk raporunu yayınlamasının ardından 2008 yılında aralarında Bosch, Cisco, Ericsson, Intel, SAP, Sun, Google ve Fujitsu gibi şirketlerin yer aldığı bir grup şirket akıllı nesneler ağında IP kullanımını artırmak ve nesnelerin interneti kavramını hayata geçirmek amacıyla IPSO Alliance adında bir iş birliği gurubu oluşturdular. Dolayısıyla 2008-2009 yılları arasında "Nesnelerin İnterneti" teknolojisi doğmuş oldu (Keertikumar ve ark., 2015).

IoT cihazların günlük hayattaki kullanım alanları bazı ana gruplar altında toplanabilir. $\mathrm{Bu}$ ana başlıklar (Dudhe ve ark., 2017):

$\checkmark$ Endüstride; çalışanların soluduğu hava kalitesinin ölçülmesi, sıcaklığın izlenmesi, gıda sanayisinde kullanılan kimyasalların seviyelerinin izlenmesi, $\checkmark$ Ak1llı ev otomasyonu ve güvenlik uygulamalarında; evlerimizde kullandığımız aletlerin bir tablet ya da akıllı telefon aracılığı ile kontrol edilmesinde,

$\checkmark$ Tarımsal üretimde; tarım arazilerinden bilgi toplayarak üretim miktarlarının ve kalitesinin artırılmasında, zararlılara karşı mücadelede ve hava koşullarına karşı önlemler alınmasında,

$\checkmark$ Sağlık alanında; hastaların gözlenmesi, uzaktaki hastaların takibi, bakım gerektiren hastaların bakım maliyetlerinin düşürülmesi,

$\checkmark$ Ulaşımda; akıllı trafik kontrolü, toplu taşıma sistemlerinin akıllı hale getirilmesi, şehir haritaları üzerinden GPS yoluyla takibi, tahmini varış sürelerinin hesaplanması, olarak gösterilebilir.

Şekil 1.1.'de Nesnelerin İnterneti teknolojilerinin kullanım alanları görsel olarak gösterilmiştir.

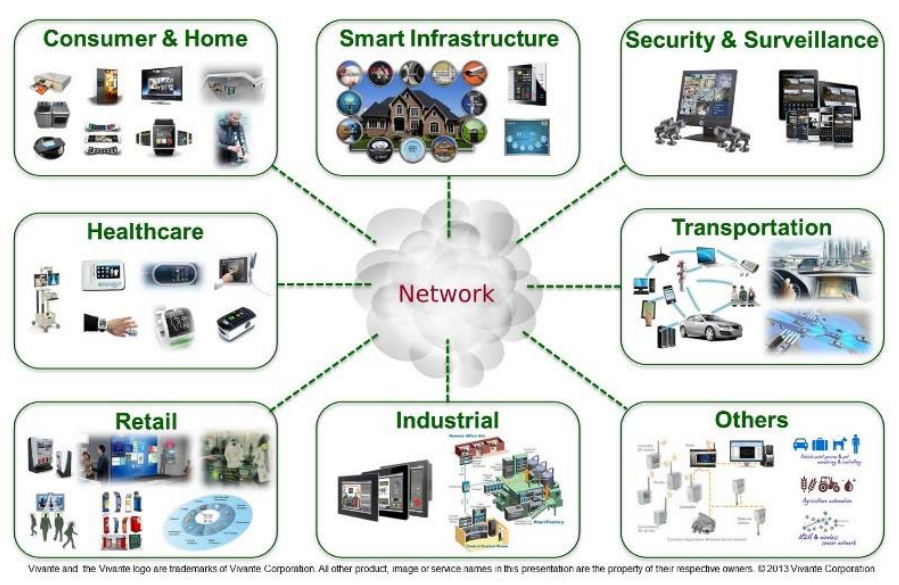

Şekil 1.1. Nesnelerin interneti uygulama alanlar

Genel olarak bir IoT sistemi çevreden bilgi toplayan sensörler, toplanan sensör verilerini aktaran ağ ve alınan verileri işleyerek karar verme ve eyleme dönüştürme süreçlerini koordine eden işlem birimlerinden oluşur (Tan ve ark., 2010). Bir IoT ekosisteminde yer alan cihazlar birbirleriyle iletişim kurarken MQTT ya da XMPP gibi cihazdan-sunucuya (D2S), DDS gibi cihazdan-cihaza (D2D), AMQP gibi sunucudansunucuya (S2S) protokolleri kullanırlar (www.electronicdesign.com, 2021). Şekil 1.2.'de bu protokoller gösterilmiştir.
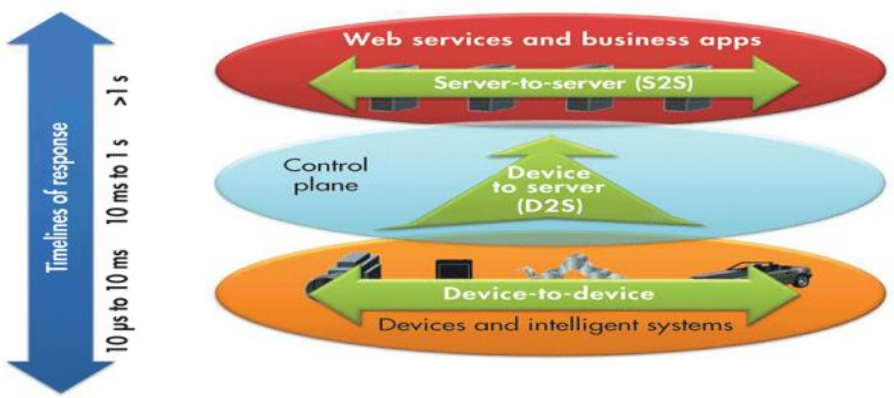

\section{Şekil 1.2. Nesnelerin interneti iletişim protokolleri}

\section{Materyal ve Metot}

$\mathrm{Bu}$ çalışmada Nesnelerin İnterneti teknolojisi hakkında yapılmış çalışmaları ve bulguları inceleyerek konu ile ilgili temel bilgileri sunmak, veri merkezi izleme ve güvenliğini sağlama konusunda donanım ve yazılım bileşenlerinden oluşan örnek bir sistem tasarlanmıştır. Çalışmada python, web araçları, 
SNMP, 1S1-nem, hareket sensörleri ve kamera kullanılarak toplanan verilerin nesnelerin interneti teknolojileri kapsamında işlenerek diğer sistemlere aktarımı sağlanmıştır. Bu sayede sistem yöneticilerine veri merkezinde meydana gelebilecek fiziksel ve güvenlik olaylarını izleme ve takip etme olanağı sağlanmıştır.

$\mathrm{Bu}$ çalışmada, Nesnelerin İnterneti teknolojisi ve kullanım alanları ile kamera, 1sı-nem ve hareket sensörleri kullanarak veri merkezinin izlenmesi ve güvenliğinin sağlanması amacıyla örnek bir uygulama üzerinde durulmuştur.

\section{Araştırma Sonuçları ve Tartışma}

\subsection{Sistemin Tasarımı}

$\mathrm{Bu}$ bölümde hazırlanan sistemin tasarımı, raspberry pi 3 model b+, arduino nano, sensörler, LCD ekran, sensör verilerinin cacti ile izlenmesi, yazılım ve kodlamaya yer verilmektedir.

Şekil 3.1' de gösterilen sistemin donanımsal bileşenlerine ait bilgilere bu bölümde yer verilmiştir.

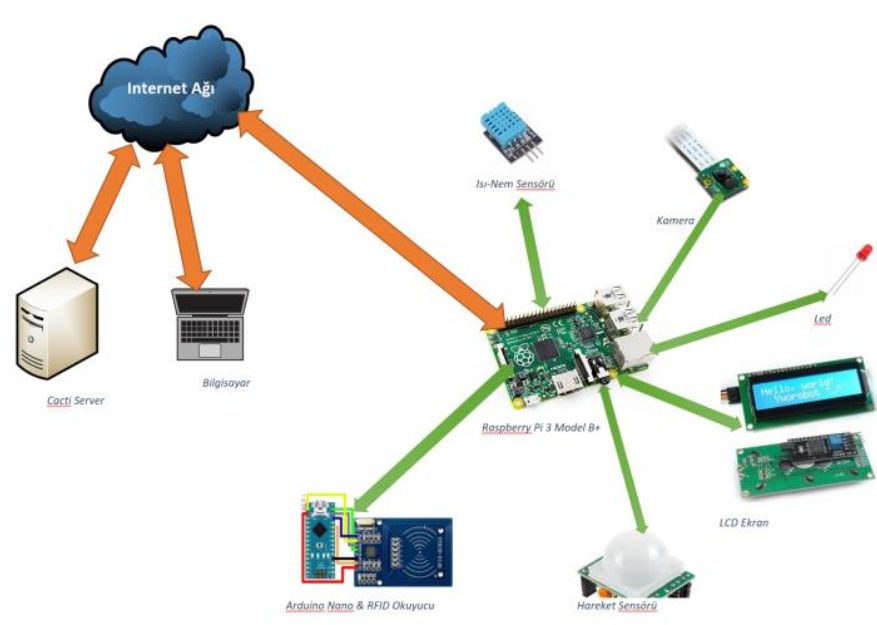

Şekil 3.1. Donanımsal bileşenler

\subsubsection{Raspberry Pi 3 Model B+}

Avuç içi boyutunda olup üzerinde 4 adet USB bağlantı noktası, bir adet ethernet bağlantı noktası, kablosuz ağ (wi-fi), 1 adet HDMI bağlantı noktası, SD kart yuvası ve 40 adet Gpio pini bulunan bir geliştirme kartıdır (Varghese ve ark., 2019). Kart üzerinde entegre Cortex -A53 grafik işlemcisi ve 64-bit Broadcom BC2837 ARM-8 dört çekirdekli işlemci ana işlemci bulunur (Saluch ve ark., 2018). Microsoft Windows IoT ya da kendisi için geliştirilmiş Linux tabanlı Raspbian OS ile çalışabilir. $\mathrm{Bu}$ araştırmada Rasbian OS işletim sistemi kullanılmıştır. Çalışmada bu kartın tercih edilmesinin nedenleri olarak üretici firmanın lisanslı sitesinde bulunan tartışma forumlarındaki bilgi paylaşımı, sensörlerin kolaylıkla eklenmesi, web, veritabanı ve diğer uygulamalar için ek bir donanıma ihtiyaç duymaması ve tümleşik yapısı sıralanabilir.

\subsubsection{Arduino Nano}

Raspberry Pi’ye göre daha küçük ATmega328 veya ATmega168 mikro işlemci tabanlı geliştirme kartıdır. Harici bir adaptöre ihtiyaç duymadan Mini USB kablo ile çalışabilir (store.arduino.cc, 2021). Çalışmada USB arayüzden bağlanan ve
RFID kart bilgilerini RC522 modül ile okuyup Raspberry Pi’ye aktaran bir kart okuyucu tasarımı amacıyla kullanılmıştır.

\subsubsection{Sensörler}

DHT11 kendiliğinden kalibre edilmiş ortam 1sısını ve nemini ölçen bir sensördür. İçerisinde NTC 1S1 ölçüm birimi ve nem ölçüm birimini barındırır. Üzerindeki 8 bit tek çipli mikro denetleyici ile hızlı, parazitsiz kaliteli ölçüm yapma imkânı sunar (Zhou ve ark., 2012). PIR sensörü üzerinde BISS0001 yongası bulunan ve pasif kızılötesi dalga yoluyla insan hareketlerini tespit eden bir sensördür. Üzerindeki yonga sayesinde analog olarak algılanan hareketi dijital çıktıya dönüştürür. Özel bir kütüphaneye ihtiyaç duymadan Python kodları yardımıyla bir anahtar gibi açma / kapama işlevlerini yerine getirir (Kaur ve ark., 2018). Çalışmada PIR sensörü tarafindan algılanan hareket Python kodları ile sisteme bağlı USB kamerayı açarak ortamın fotoğrafını çekip sistem yöneticisine bilgi e - postası göndermek amacıyla kullanılmıştır.

\subsubsection{LCD Ekran}

$\mathrm{Bu}$ araştırmada sensörlerden gelen sıcaklık ve nem verileri ile cihaza ait IP adresini göstermek için 16 karakter x 2 satır özelliğinde I2C LCD ekran kullanılmıştır. Şekil 3.2'de örnek bir görüntüye yer verilmiştir.

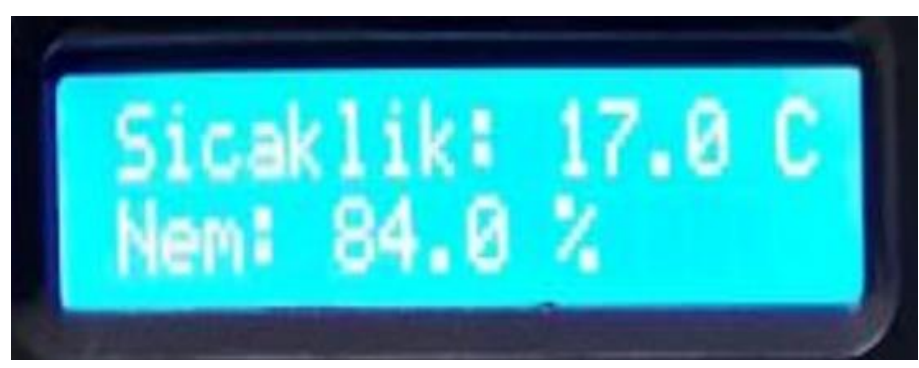

Şekil 3.2. I2C LCD Ekranda sicaklık ve nem bilgilerinin gösterimi

\subsubsection{Sensör Verilerinin Cacti ile İzlenmesi}

Sensör verilerinin izlenmesinde açık kaynak kodlu NMS olan Cacti kullanılmıştır. Cacti, Php, MySQL, RRD ve SNMP servislerini kullanarak cihazlardan topladığı verileri sistem yöneticilerine çeşitli grafik türleriyle sunan bir ağ izleme aracıdır. Sistem yöneticileri bilgisayar, tablet ya da akıllı telefondan erişerek bir takım yönetimsel işlemleri yerine getirebilir (Li ve ark., 2016). Sensör verilerinin Cacti tarafindan SNMP protokolüyle okunabilmesi için Raspberry Pi üzerine SNMP modülü ve MIB (Management Information Base) bileşenleri de kurulmuştur. Şekil 3.3'te Cacti sunucusu üzerinde Raspberry Pi sensörlerinden 1sı ve nem verisini alan konsol çıktısı gösterilmiştir. 


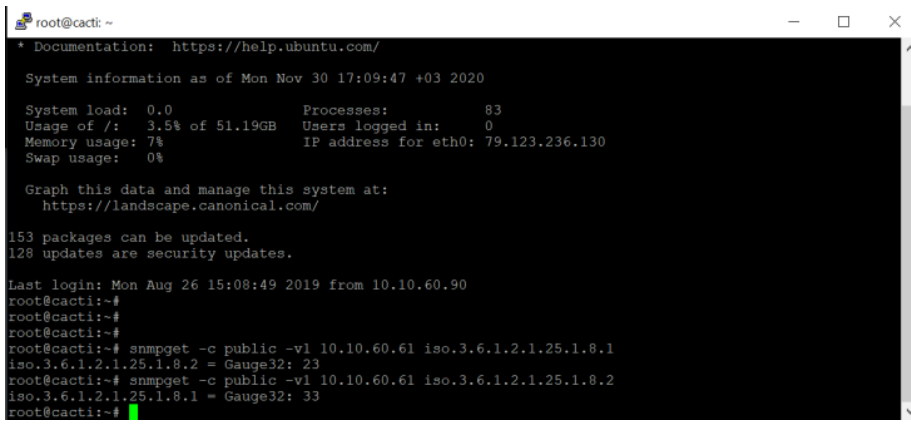

Şekil 3.3. SNMP ile sensör verilerinin konsol çıktısı görünümü

Cacti sunucusu üzerinde sensör verilerinin anlamlı bir şekilde görüntülenmesi ve sensörlerden gelen verilerin belirlenen eşik değerlerden yüksek olması durumunda sistem yöneticisine e-posta gönderilmesi olayını tetikleyecek şablonlar tanımlanmıştır. Örnek şablonlar Şekil 3.4 ve Şekil $3.5^{\prime}$ te gösterilmiştir.

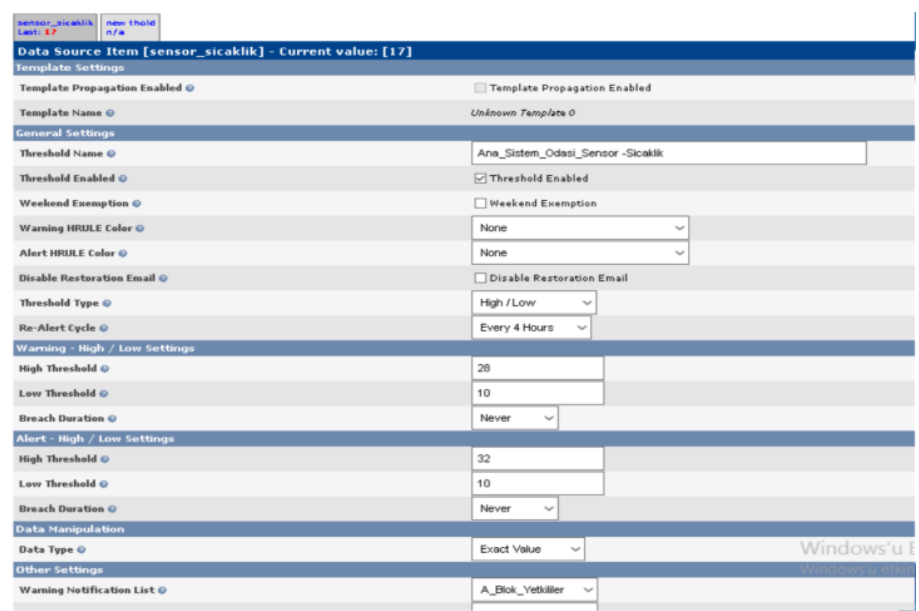

Şekil 3.4. Sicaklık ve nem şablonlarının cacti sunucusunda tanimlanmasi

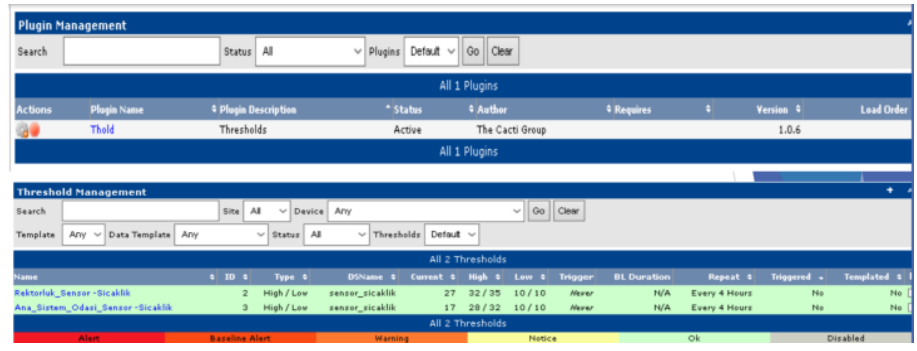

Şekil 3.5. Alarm şablonlarının cacti sunucusunda tanımlanması

Şekil 3.5'te oluşturulan alarmlar ortamdaki 1sı ve nem değişikliğini Raspberry Pi'den aldığı verilerle karşılaştırır. Isı değerleri belirlenen düzeyin üzerine çıktığında sunucu üzerinde çalışan ve elektronik posta sunucusu ile iletişim kuracak şekilde ayarlanmış SMTP protokolünü kullanarak sistem yöneticisine bu durumu rapor eden bir e-posta gönderir. Sistem tarafindan gönderilen e-posta örneği Şekil 3.6' da gösterilmiştir.
ALERT -> WARNING: Rektorluk_Sensor -Sicaklik Changed to Warning Threshold with Value 34

Device: Rektorluk_Sensor $(10.10 .60 .20)$

URL: Link to Graph in Cacti

Message: ALERT -> WARNING: Rektorluk_Sensor -Sicaklik Changed to Warning Threshold with Value 34

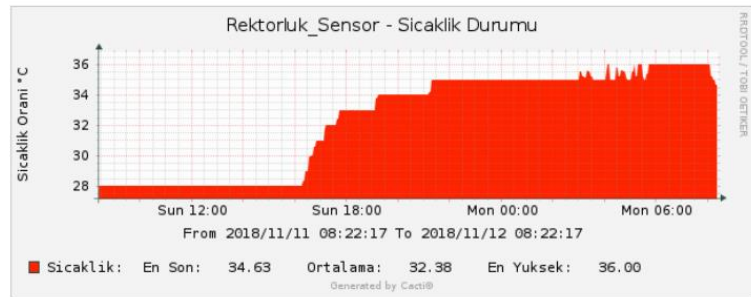

Şekil 3.6. Sistem tarafindan gönderilen alarm e-posta içeriği

\subsection{Yazılım ve Kodlama}

$\mathrm{Bu}$ araştırmada sistemin ana bileşeni olan Raspberry $\mathrm{Pi}$ kartına Debian tabanlı Raspbian OS işletim sistemi kurulmuştur. Sensörlerden veri almak ve alınan verileri kullanarak işlem yapmak amacıyla kullanılan scriptler için Python programlama dilinden yararlanılmıştır. Isı ve nem sensörlerinden ortam değerlerini alabilmek amaciyla Python Adafruit DHT kütüphanesi kullanılmıştır. DHT11 sensöründen veri okuma belirli bir sinyal protokolü gerektirdiğinden bu kütüphanenin kullanımı veri okumayı kolaylaştırır (Zhou ve ark., 2020). Isı ve nem bilgilerini okuyarak SNMP verisine dönüştüren örnek Python kodları aşağıda gösterilmiştir.

\subsubsection{Isı Kodu}

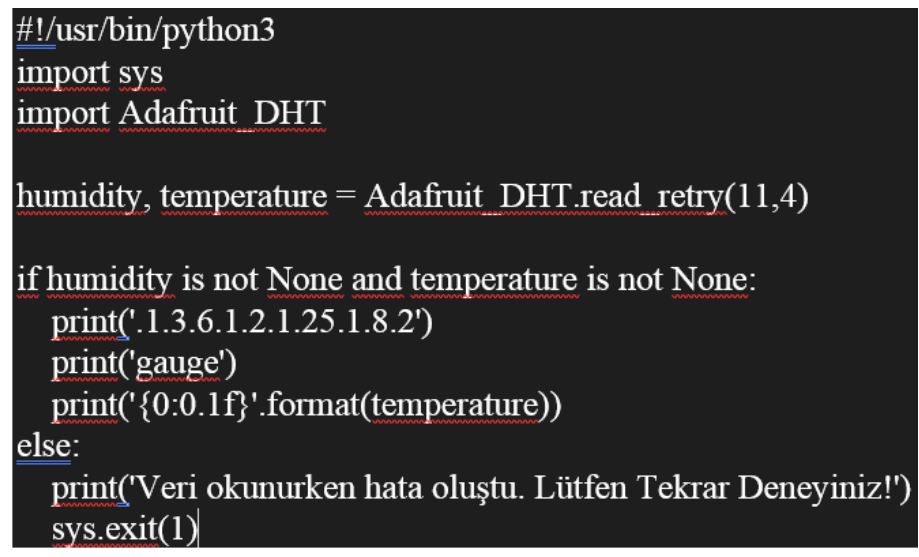

\subsubsection{Nem Kodu}

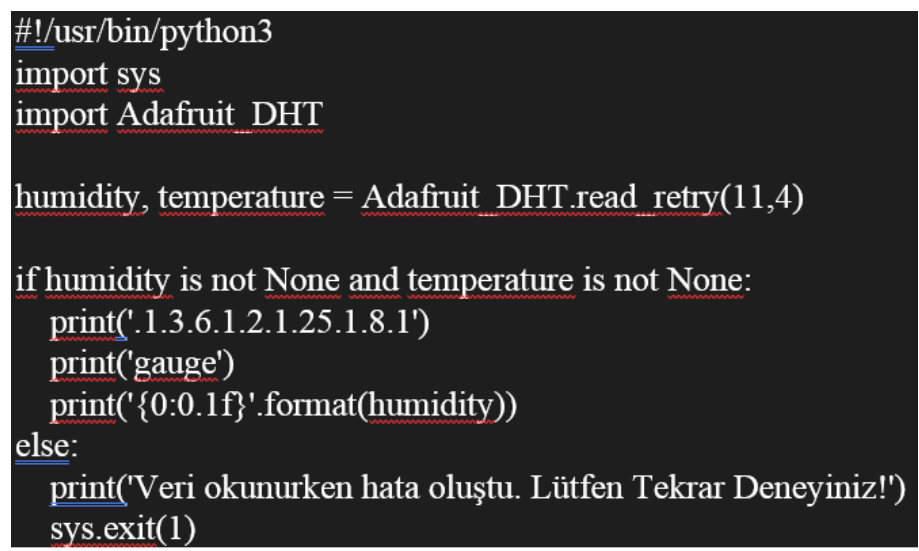


Veri merkezinin güvenliğini sağlamak amacıyla izole edilen ortama giriş çıkış yapan kişilerin kameradan anlık görüntüsünü almak amacıyla fswebcam kütüphanesi kullanılmıştır. İlgili kütüphaneye ait yordamı tetiklemek amaciyla da PIR sensöründen istifade edilmiştir. GPIO pinlerine bağlı olan PIR sensörü hareketi algıladığında dijital bir veri gönderir. Sistem arka planda sürekli olarak çalışmakta olan Python kodları aracılığıyla gelen bu veriyi algılar ve fswebcam yordamını çalıştırır. Çalışan bu yordam sisteme USB arayüzünden bağlı kameraya ulaşarak ortamın anlık görüntüsünü JPEG formatında kaydeder. Kaydedilen bu dosya başka bir Python scripti vasıtasıyla sistem yöneticisine e-posta olarak gönderilir. Aşağıda örnek kodlar verilmiştir. Ayrıca sistemin gönderdiği e-posta ile ilgili ekran görüntüsü de Şekil 3.7'de gösterilmiştir.

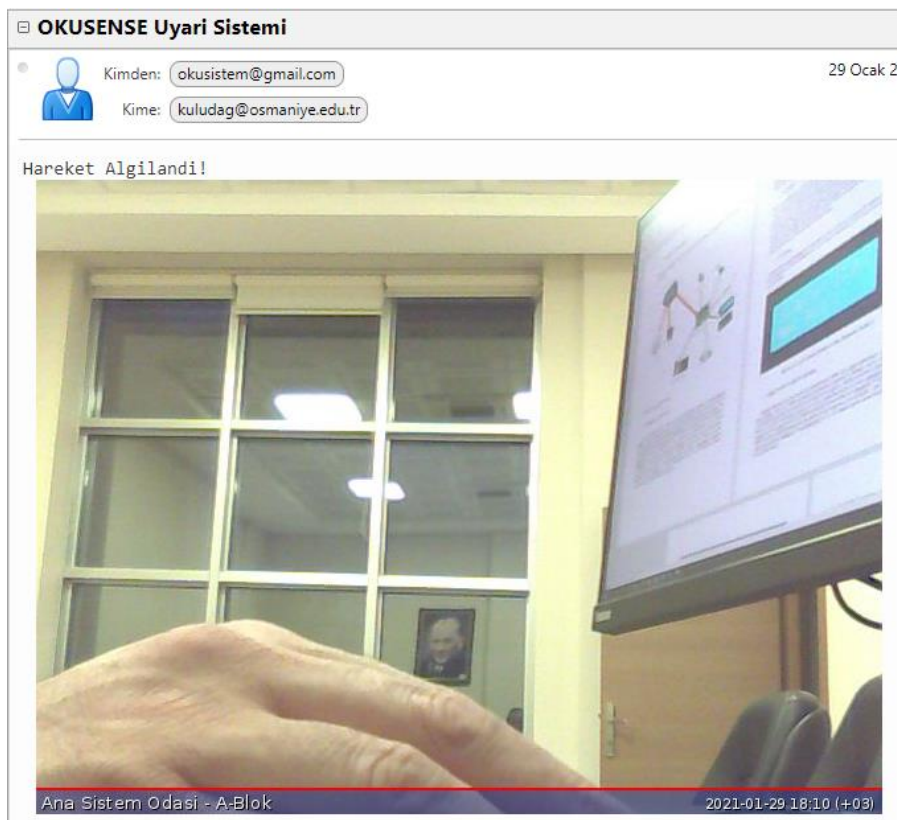

Şekil 3.7. Sistem tarafindan gönderilen anlık ortam fotoğrafina ait e-posta içeriğ $i$

\subsubsection{PIR Sensörü Yardımıyla Ortam Görüntüsünü Alan Kod Örneği}

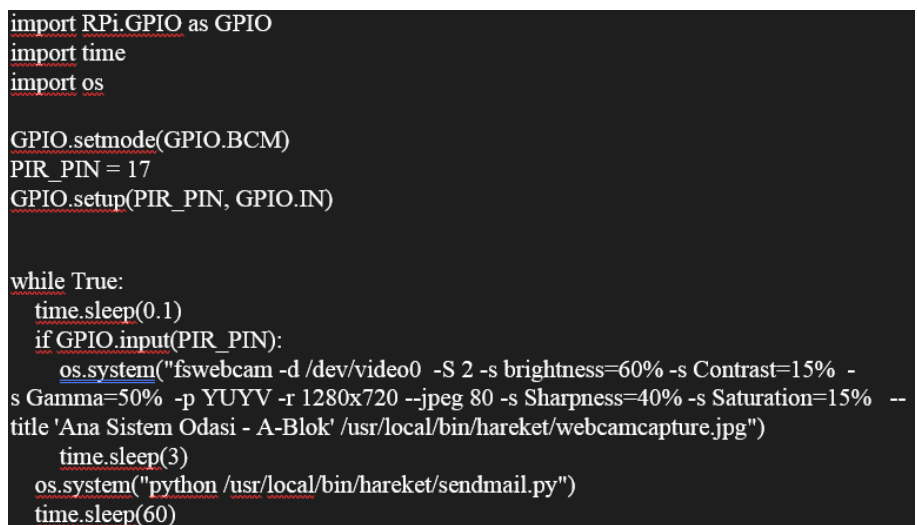

\subsubsection{Alınan Görüntüyü Sistem Yöneticisine E - Posta Gönderen Kod Örneği}

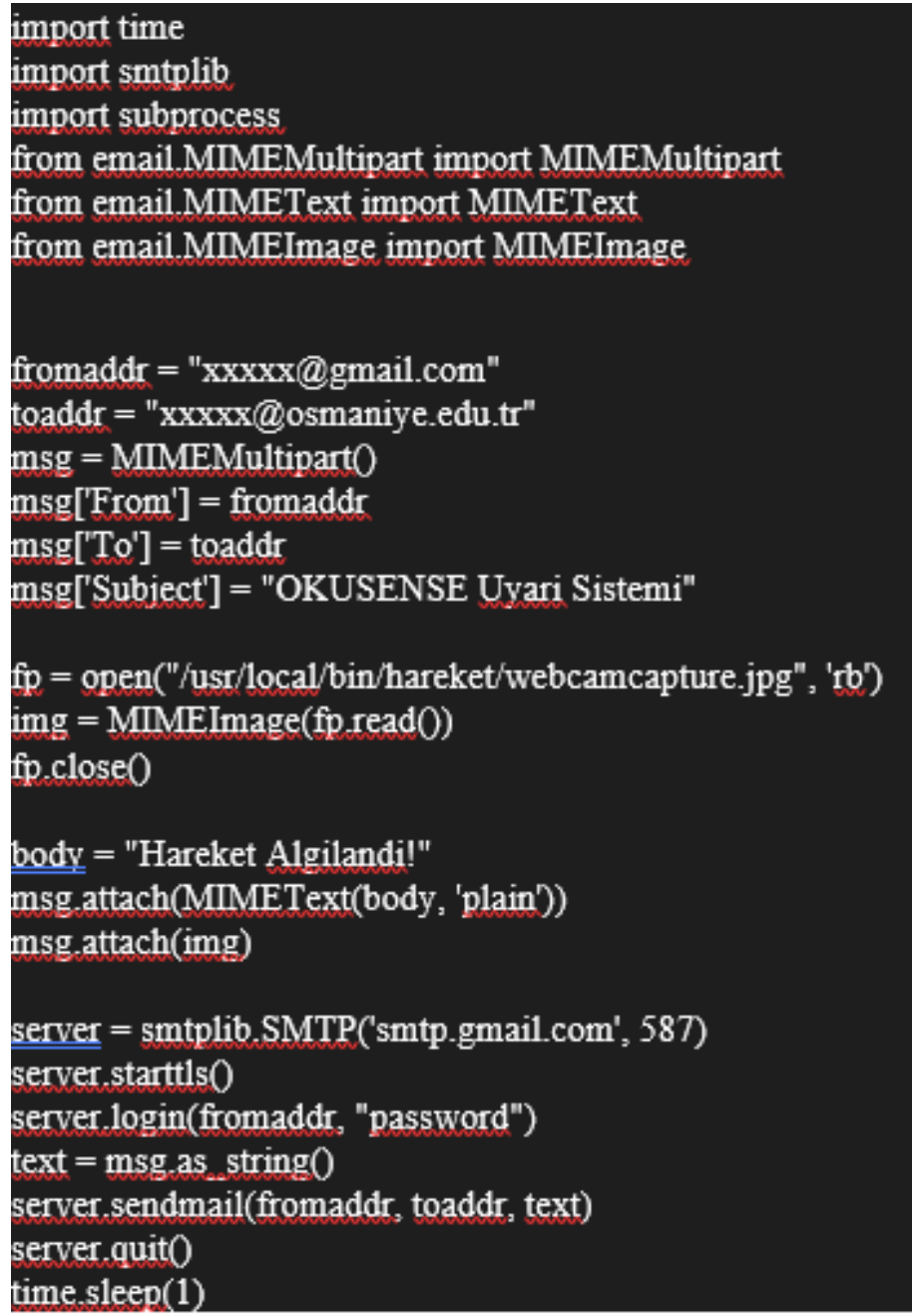

\section{Sonuç}

Günümüzde teknoloji ve iletişim ağlarında yaşanan gelişmeler neticesinde insan-makine etkileşimi kavramı popülerliğini artık makine-makine etkileşimi kavramına bırakmıştır. Makinelerin birbirleriyle etkileşime girerek özellikle yapay zekâ teknolojilerindeki gelişmelerin 1şı̆̆ı altında kendi kendine karar verme, birbirleriyle ortak bir dil kullanması ve yapay sinir ağları vasıtasıyla öğrenmesi günümüz teknolojisinde her ne kadar henüz emekleme aşamasında da olsa çok büyük ve devrim niteliğindeki gelişmeler olarak tarihe geçeceği aşikardır.

Makine-makine etkileşiminde sensörler kuşkusuz büyük bir öneme sahiptir. Son y1llarda özellikle bu teknolojilerin ucuza mal edilmesi ve basitleştirilmesi kullanmakta olduğumuz alet ve makinaların yani nesnelerin birbirleriyle olan iletişimini de artırmıştır. Nesnelerin İnterneti olarak adlandırılan bu kavram teknolojide bir devrim niteliğindedir. Sanayide, tarımda, sağlık alanında, eğitimde, ulaşımda, kişisel ürünlerde, akıllı ev ve otomasyon sistemlerinde, otomotiv sektöründe sıklıkla kullanılmaktadır. Endüstri 4.0 dediğimiz çağımızın sanayi devriminin gerçekleşmesindeki esas oyunculardan biri haline gelen nesnelerin interneti özellikle mobil ağlarda yaşanan gelişmeler de dikkate alındığında hayatımızın her alanında daha çok yer alacaktır. 
$\mathrm{Bu}$ çalışmada nesnelerin interneti teknolojisini kullanarak bir veri merkezindeki sensörler yardımıyla ortam verilerini toplayıp işleyerek sistem yöneticisine ya da başka bir sisteme gönderen bir prototip sistem tasarlanmıştır. Sistemde Raspberry Pi 3 B+ model arm-8 dört çekirdekli 64 bit işlemcili geliştirme kartı ve bazı sensörler kullanılmıştır. Çalışma sonunda tasarlanan prototipe ait nihai görüntü Şekil 4.1'de gösterilmiş̧tir. Çalışmada bir veri merkezinin izlenmesinde ucuz, tek bir sistem üzerinde birçok sensör verilerinin toplandığ 1 , bu verileri diğer sistemlerle paylaşabilen bir sistem tasarlamak amaçlanmıştır. Sonraki çalışmalar için ise sistem üzerine yapay zekâ ve yapay sinir ağları teknolojilerini entegre ederek sistemin kendi başına karar vermesini, aksiyon almasını sağlamak önerilmektedir.

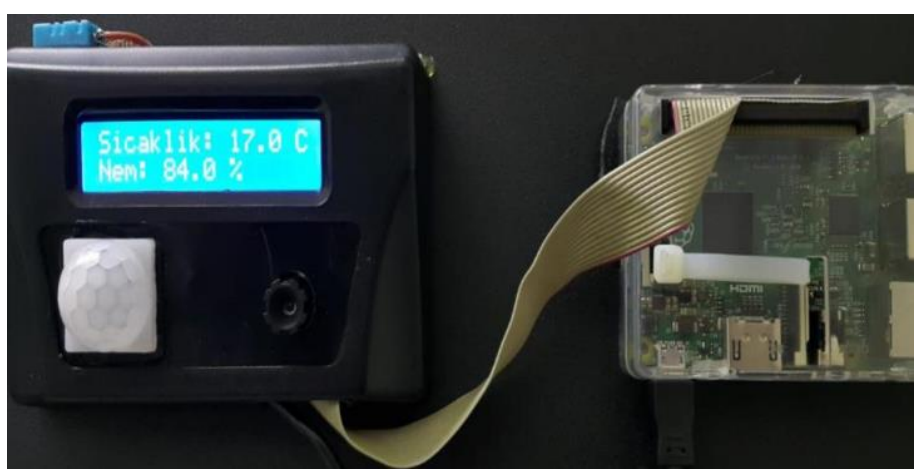

Şekil 4.1. Çalışma sonucunda geliştirilen prototip model

\section{Kaynakça}

Baz, F. Ç. (2018). New Trends in E - Learning. Trends in E Learning (Ed. Mahmut Sinecen). Intechopen: London.

Carrillo, E., Benitez, V., Mendoza, C., \& Pacheco, J. (2015). IoT framework for smart buildings with cloud computing. 2015 IEEE First International Smart Cities Conference (ISC2), Guadalajara, pp. 1-6. doi: 10.1109/ISC2.2015.7366197.

Dudhe, P. V., Kadam, N. V., Hushangabade, R. M., \& Deshmukh, M. S. (2017). Internet of Things (IOT): An overview and its applications. International Conference on Energy, Communication, Data Analytics and Soft Computing (ICECDS), Chennai, pp. 2650-2653, doi: 10.1109/ICECDS.2017.8389935.

Hammami, A. (2019). Smart Environment Data Monitoring. 2019 International Conference on Computer and Information Sciences (ICCIS), Sakaka, Saudi Arabia, pp. 1-6, doi: 10.1109/ICCISci.2019.8716469.

https://www.electronicdesign.com/technologies/iot/article/21798 493/understanding-the-protocols-behind-the-internet-ofthings, 2021.

https://www.ericsson.com/en/reports-and-papers/whitepapers/cellular-networks-for-massive-iot--enabling-lowpower-wide-area-applications, 2021.

https://store.arduino.cc/usa/arduino-nano, 2021.

https://tr.wikipedia.org/wiki/Nesnelerin_interneti, 2021.

Kaur, B., Pateriya, P. K., \& Rai, M. K. (2018). An Illustration of Making a Home Automation System Using Raspberry Pi and PIR Sensor. International Conference on Intelligent
Circuits and Systems (ICICS), Phagwara, pp. 439-444, doi: 10.1109/ICICS.2018.00095.

Keertikumar M., Shubham M. \& Banakar, R. M. (2015). Evolution of IoT in smart vehicles: An overview. 2015 International Conference on Green Computing and Internet of Things (ICGCIoT), Noida, pp. 804-809, doi: 10.1109/ICGCIoT.2015.7380573.

Li, C. C., Ji, Z. S., Wang, F., Wang, P., Wang, Y., \& Zhang, Z. C. (2016). The network monitoring system based on Cacti for EAST. IEEE-NPSS Real Time Conference (RT), Padua, pp. 1-5, doi: 10.1109/RTC.2016.7543086.

Liu, Q., Ma, Y., Alhussein, M., Zhang, Y., \& Peng, L. (2016). Green data center with IoT sensing and cloud-assisted smart temperature control system. Computer Networks 101, pp. 104-112, doi:10.1016/j.comnet.2015.11.024.

Romkey, J. (2017). Toast of the IoT: The 1990 Interop Internet Toaster. IEEE Consumer Electronics Magazine, 6(1), pp. 116-119, doi: 10.1109/MCE.2016.2614740.

Saluch, M., Tokarski, D., Grunniewski, T., Chodyka, M., Nitychoruk, J., Wolinski, P., \& Adamczewski, G. (2018). Raspberry PI 3B+ microcomputer as a central control unit in intelligent building automation management systems. In MATEC Web of Conferences. 196, p. 04032. EDP Sciences.

Tan, L., \& Wang, N. (2010). Future internet: The Internet of Things. 3rd International Conference on Advanced Computer Theory and Engineering (ICACTE), Chengdu, pp. V5-376-V5-380, doi: 10.1109/ICACTE.2010.5579543.

Varghese, L., Deepak, G., \& Santhanavijayan, A. (2019). An IoT Analytics Approach for Weather Forecasting using Raspberry $\mathrm{Pi} 3$ Model $\mathrm{B}+$, Fifteenth International Conference on Information Processing (ICINPRO), Bengaluru, India, pp. 1-5, doi: 10.1109/ICInPro47689.2019.9092107.

Zhou, Y., Zhou, Q., Kong, Q., \& Cai, W. (2012). Wireless temperature \& humidity monitor and control system. 2nd International Conference on Consumer Electronics, Communications and Networks (CECNet), Yichang, pp. 2246-2250, doi: 10.1109/CECNet.2012.6201725.

Zhou, K., \& Yuan, Y. (2020). A Smart Ammunition Library Management System Based on Raspberry Pie. Procedia Computer Science. 166, pp.165-169, doi:10.1016/j.procs.2020.02.041. 